(Aus dem Institut zur Erforschung der Infektionskrankheiten in Bern [Direktor: Prof. G. Sobernheim].)

\title{
Untersuchungen über die Desinfektionswirkung der Jodtinktur.
} Von

\author{
Dr. L. Rachmilewitsch.
}

\section{Einleitung.}

Seitdem durch Grossich im Jahre 1909 für die Vorbereitung des Operationsfeldes bei chirurgischen Operationen die Jodtinktur in Form eines einfachen Hautanstriches empfohlen worden ist, hat dieses Verfahren in der chirurgischen Praxis weitgehende Anwendung gefunden. Die Jodpinselung stellt auch heute noch das wohl am meisten für diesen Zweck geübte Verfahren dar und hat sich nach den vorliegenden Erfahrungen bewährt. Wenn auch über manche technische Einzelheiten die Ansichten der Autoren auseinandergehen und die Grossichsche Originalmethode daher in verschiedener Hinsicht Modifikationen erfahren hat, so stimmen die Berichte jedenfalls in wesentlichen darin überein, daß bei sachgemäßer Anwendung der Jodtinktur die Möglichkeit aseptischer.Operationen in ausreichendem $\mathrm{MaBe}$ gewährleistet wird.

Das Grossichsche Verfahren besteht bekanntlich darin, daß die Haut rings um die Wunde eines Verletzten oder die Haut des Operationsfeldes nicht mit Seife und Wasser behandelt, sondern ohne jede Art von Waschung trocken rasiert und alsdann nur mit Jodtinktur bestrichen wird. Die Neuerung dieser Methode und ihren Erfolg erblickt Grossich nach seinen eigenen Worten in der Tatsache, daß „die Bestreichung der trockenen Haut mit Jodtinktur eine vollkommene Sterilisierung derselben bewirkt, so daß der heißeste Wunsch der Aseptik endlich erfüllt wird".

Die Empfehlung der Jodtinltur in dieser Form der Anwendung gründete Grossich allein auf eine mehrjährige klinische Erfahrung an einem großen Krankenmaterial. Eigene experimentelle Untersuchungen hinsichtlich der desinfizierenden Wirkung der Jodtinktur auf die Bakterien der Haut standen ihm nicht zur Verfügung. Er konnte sich nur auf die nachträglich von Walther und Touraine angestellten Experimente berufen. 
Es ist höchst auffällig, daß auch heute über die Wirkungsweise der Jodtinktur, sowohl im allgemeinen, wie ganz besonders bei der Anwendung in Form des Hautanstrichs noch keine einheitlichen Anschauungen bestehen. Die Laboratoriumsversuche lieferten ziemlich ungleichmäßige Ergebnisse und haben bisher zu keiner völligen Klärung geführt.

Die Art und Weise, wie die ganze Frage der exakten Prüfung unterworfen wurde, ist eine sehr verschiedene. Teils hat man Reagensglasversuche, teils Experimente an der Tierhaut, teils solche an der Menschenhaut vorgenommen. Auch die Technik der Desinfektionsprüfung wurde verschieden gehandhabt, so daß es nicht wunder nehmen kann, daB zum Teil ganz widersprechende Resultate erzielt wurden.

Unter diesen Umständen habe ich es gern unternommen, mich über die Wirkung der Jodtinktur durch eigene Versuche zu unterrichten.

Ehe ich auf die Darstellung dieser Versuche eingehe, seien die bisher in der Literatur vorliegenden Angaben kurz zusammengestellt.

Die ersten Untersuchungen wurden, wie erwähnt, von Walther und Touraine angestellt. Sie fanden, wenn sie Hautstückchen des jodierten Operationsfeldes herausschnitten und auf Nährböden übertrugen, daß die Jodtinktur gewöhnlich schon 5, ganz sicher aber 10 Minuten nach dem Jodanstrich auf der trockenen Haut alle Keime vernichtet hatte. In Parallelversuchen mit Hautstückchen von Patienten, die zuerst mit Wasser, Seife, Äther und Alkohol und dann erst mit Jodtinktur behandelt waren, wuchsen dagegen jedesmal auf den Nährsubstraten (Agar) reichliche Kolonien (Staphylokokken). Dasselbe Resultat ergaben Versuche, die sie an der Rückenhaut von Meerschweinchen angestellt haben. Auch hier erwiesen sich nach Jodpinselung. der trocken rasierten Haut die Proben bei Utbertragung auf Nährböden im allgemeinen als steril, während nach feuchter Reiniging, Desinfektion und Jodpinselung stets noch cine Anzahl von Keimen zur Entwicklung gelangte. In Übereinstimmung mit diesen Ergebnissen haben die Autoren durch Behandlung von Hautschnitten mit Silbernitrat nachweisen können, daß die Haut sich nur dann mit Jodtinktur imbibiert, wenn man trocken arbeitet, nicht aber nach gewöhnlichen Waschungen.

In besonders eingehender Weise hat $\mathrm{K}$ utscher die Wirkung der Jodtinktur bei der Hautdesinfektion geprüft. Seine Versuche wurden im Hinblick auf die sorgfältige Technik und die einheitlichen Ergebnisse als maßgebend betrachtet, weshalb sie etwas ausführlicher mitgeteilt seien.

Kutscher rieb einem Kaninchen virulente, von 48stündiger Agarkultur gewonnene und mit etwa $1 \mathrm{ccm}$ physiologischer NaCl-Lösung aufgeschwemmte Milzbrandsporen auf die rasierte Bauchhaut ein. Nach 24 Stunden wurde die infizierte Haut, die vollkommen trocken war, zweimal hintereinander in einem Zeitabstand von 15 Minuten mit offizineller 10 proz. Jodtinktur bepinselt. 10 Minuten nach dem 
zweiten Jodanstrich wurden aseptisch aus der jodierten Haut Stücke herausgeschnitten und weißen Mäusen in eine Hauttasche verimpft. Ferner wurden von der mit Jod behandelten Haut mittels steriler Messerklinge oberflächliche Hautpartien abgeschabt, in steriler $\mathrm{NaCl}$-Lösung aufgeschwemmt und mit $45^{\circ}$ warmem Agai zu Platten verarbeitet. Das Jod war nach der Excision bzw. vor der Verimpfung neutralisiert worden ( $10 \%$ Natriumthiosulfat). 3 von den 4 auf diese Weise geimpften weißen Mäusen gingen nach 2-3 Tagen an bakteriologisch nachweisbarem Milzbrand ein. Das 4. Tier war krank, erholte sich aber nachher. Auf sämtlichen Agarplatten wuchsen in 24 Stunden sehr reichlich Milzbrandbacillen.

Der Ausfall dieser Versuche steht somit in direktem Widerspruch mit den Angaben von Walther und Touraine und mit der Lehre Grossichs, wonach die Jodtinktur keimtötend auf die Hautbakterien wirken soll.

Analoge Versuche, die mit vegetativen Bakterienformen (B. pyocyaneus) an Kaninchen und Meerschweinchen vorgenommen wurden, gaben Kutscher das gleiche Resultat.

Weitere Versuche stellte Kutscher in vitro an. Er benutzte zu diesem Zwecke Seidenfäden, die mit Milzbrandsporen bzw. Staphylokokken und B. pyocyaneus imprägniert waren. Die infizierten Seidenfäden (getrocknet) wurden verschieden lange Zeit in 10 proz. Jodtinktur belassen und auf Bouillon übertragen. Vor der Utbertragung auf den Nährboden wurde das Jod mit Natriumthiosulfat neutralisiert und mit sterilem destillierten Wasser nachgespült. Das Ergebnis dieser Versuchsreihe war, daß selbst nach 60 Minuten langer Einwirkung der Jodtinktur noch sämtliche Testbakterien lebensfähig blieben.

Die Gesamtheit seiner Untersuchungsergebnisse fïhrte $K$ utscher daher zu dem Schluß, daß die alkoholisehe Jodtinktur als solche überhaupt keine nenmenswerten bactericidon Eigenschaften bositzt, im Gegensatz zu den rein wässerigen Lösungen des Jods. Wr erblickt die Ursache für die gïnstige Wirkung der Jodtinkturpinselung nach Grossich nicht in einer Keimabtötung, sondern wesentlich in einer Fixierung der Hautkeime. Nach ihm bleibt nur die Möglichkeit der Annahme, daß durch, die Jodtinktur die Keimabgabefähigkeit der Haut stark herabgesetzt werden muß". Diese Herabsetzung werde durch den konzentrierten Alkohol im Verein mit der ebenfalls austrocknenden Wirkung des Jods bedingt.

Damit war der Fragestellung eine ganz bestimmte Richtung gegeben: Beruht die Wirkung der Jodtinktur wirklich nur auf Keimfixierung oder auf Keimabtötung?

Den gleichen Standpunkt wie K utscher vertritt Lanz. Er verglich in seinen Versuchen die Grossichsche Methode mit anderen Verfahren 
der Hautdesinfektion, indem er bei aseptischen Operationen kleine Hautstückchen excidierte und auf Agar verimpfte; er wählte dabei stets gleiche Körpergegenden. Bei der Grossichschen Methode gingen in 3 von 6 Versuchen Keime auf, die Methoden nach Fürbringer, Schumburg und Lanz lieferten günstigere Resultate.

Auch bei einer anderen Versuchsanordnung, wobei die Seidennähte 2-3 Tage nach der Operation auf Platten verimpft wurden, stand die Grossichsche Methode an Sicherheit der Wirkung hinter den anderen Verfahren zurück.

Den beiden eben erwähnten Autoren (Kutscher, Lanz) schließt sich auch Decker an. Ausgeschnittene Hautstückchen, die 2 mal mit Jodtinktur gepinselt waren, benutzte er zu Züchtungsversuchen. Ferner kratzte er von der bejodeten Haut oberflächliche Hautpartien ab und stellte hiermit gleichfalls Kulturversuche an. Die Aussaat der Proben erfolgte in Nährbouillon und auf Agarplatten. Das Ergebnis war, daß meist Bakterien, auch Staphylokokken und Streptokokken, zur Entwicklung gelangten. Decker spricht daher der Jodtinktur eine Desinfektionswirkung ab und glaubt mit Kutscher, daß nur die Keimabgabefähigkeit der Haut herabgesetzt wird.

Einen ganz anderen Standpunkt zu dieser Frage nehmen Bérard und Chattot an. Ihre Versuche bestätigen durchaus die Grossichsche Auffassung. Sie gingen so vor, $\mathrm{da} B$ sie die Fingerspitzen nach Grossich mit Jodtinktur bepinselten und den Erfolg nun durch Fingerabdrücke auf Agar prüften. Es ergab sich, daß die so bestrichenen Nährböden stets steril blieben. Ferner stellten sie folgenden Versuch an. Die Fingerspitzen von Leichen tauchten sie in flüssige virulente Kulturen von Staphylokokken und Streptokokken ein und, nach dem Trockenwerden, einen Augenblick in Jodtinktur. Es fanden sich alsdann (im Staphylokokkenversuch) bei 30 Abdrücken auf Agar nur 3 mal Staphylokokkenkolonien, nach Streptokokkenimprägnierung (25 Abdrücke) nur 1 mal Kolonien, während die Kontrollimpfungen zahllose Kolonien aufgehen ließen.

Auch Myauchi machte mit den Fingern von Ärzten, Dienern und Wärterinnen, die er mit Jodtinktur bestrich, Kulturversuche. Nur auf wenigen Nährböden gingen Bakterienkolonien auf. Alkoholdesinfektion. wirkte schlechter.

Zum gleichen Resultat kam Osaki, der an seinen eigenen Händen experimentierte und ebenfalls die Wirkung der Jodtinktur mit der des Alkohols verglich. Zur Abimpfung verwandte er die Wattebauschmethode. Dabei verschärfte er die Prüfungstechnik noch insofern, als er die jodierte Haut vor der Probeentnahme zwecks Neutralisierung des Jods mit 2 proz. Natriumthiosulfatlösnng behandelte. Außerdem stellte er die Desinfektionswirkung sowọl der Jodtinktur als auch des 
Alkohols nicht nur in der gewöhnlichen Weise fest, sondern auch so, da $\dot{\beta}$ er die desinfizierte Haut zunächst noch 7-10 Minuten lang in warmen, sterilem Wasser badete. Er erhielt foldende Resultate:

Keimzahlen.

\begin{tabular}{l|c|c|c}
\hline \hline Methode & $\begin{array}{c}\text { Vor der } \\
\text { Desinfektion }\end{array}$ & $\begin{array}{c}\text { Nach der } \\
\text { Desinfektion }\end{array}$ & $\begin{array}{c}\text { Nach dem } \\
\text { Bade }\end{array}$ \\
\hline \hline Alkohol. . . & über 100 & 10,8 & 74,7 \\
Grossich . . . & über 100 & 0,7 & 1,8
\end{tabular}

Die Jodtinktur lieferte also erheblich günstigere Resultate als der Alkohol, namentlich nach Erweichung der Haut im Wasserbade. In der Regel bewirkte die Hautpinselung schon nach 1-2 Minuten eine hochgradige Keimverminderung. Osaki schreibt der Grossichschen Methode bei exakter Ausführung sichere Desinfektionswirkung zu.

In besonders gründlicher Weise ist die Frage der Jodwirkung von Noguchi studiert und unter Berücksichtigung des gesamten vorliegenden Tatsachenmaterials zum Gegenstand umfassender experimenteller Untersuchungen gemacht worden. Es sei auf diese wichtige Arbeit etwas näher eingegangen. Die Versuche an der menschlichen Haut wurden von ihm zunächst so vorgenommen, daß er die betreffenden Hautstellen (Bauch, Fingerspitzen, Bein, Fuß) mit Jodtinktur $(10 \%$ Jod in $\mathbf{8 6} \%$ Alkohol) bepinselte und nun mit Hilfe der ,Zahnbürstenmethode ${ }^{\text {("1) }}$ ) auf Keimgehalt prüfte.

Das Resultat war, daB er fast stets Keimfreiheit erzielte, wogegen bei den anderen, zum Vergleich herangezogenen Méthoden (Für bringer, Miculicz) Keime häufiger und in größerer Zahl aufgingen. Das Ergebnis änderte sich, als in einer weiteren Versuchsreihe vor der Abimpfung zunächst eine Neutralisation der Jodtinktur mit 12 proz. Lösung von Natriumthiosulfat vorgenommen wurde. Auch hier wurdc zwar gelegentlich Keimfreiheit festgestellt, aber nur wenn die Zahl der Hautkeime schon vor der Desinfektion gering war. Sonst $d . h$. bei stärkerem Bakteriengehalt der Haut gingen nach zwei und selbst nach 10 Minuten langer Einwirkung des Jodanstrichs noch ziemlich zahlreicho Kolonien auf. Zur Verstärkung der Jodwirkung ließ Noguchi ferner

1) Dieses Verfahren, dem Noguchi besondere Bedeutung für dio Prüfung beimißt, besteht darin, daß er zur Materialentnahme eine kleine, feine Zahnbürste wählt, deren Borsten in halber Länge abgeschnitten sind; die Bürste wird im Dampfe sterilisiert. Vor der Keimentnahme werden die Spitzen der Borsten in steriles Glycerin getaucht und damit die Haut befeuchtet, um die Keime besser abnehmen zu können. Die Bürste wird danach in ein mit $2 \mathrm{ccm}$ Wasser oder Kochsalzlösung gefülltes Röhrchen gebracht und dieses eine Minute lang gleichmäBig geschüttelt. Das Röhrchen wird mit $8 \mathrm{ccm}$ gelöstem, bis auf $40^{\circ}$ abgekühltem 0,4 proz. Zuckeragar gefüllt, Nachdem die gesamte flïssige Masse einige Male geschüttelt, wird sie auf Petrischalen verarbeitet. 
dem ersten Jodanstrich nach 10 Minuten einen zweiten folgen und entnahm hierauf zu verschiedenen Zeiten nach vorangehender Neutralisierung wiederum Proben. Auch bei diesem Verfahren wurde völlige Keimfreiheit zwar nicht sicher erzielt, wohl aber eine weitere Keimverminderung festgestellt, und vor allen Dingen die wichtige Tatsache ermittelt, daß die Keimzahl der jodierten Haut mit der Zeit fortschreitend abnimmt. Ob die Haut vor dem Jodanstrich gewaschen wird oder nicht, fand Noguchi belanglos. Die Untersuchungsergebnisse waren die gleichen, wenn nur darauf geachtet wurde, daß auch bei der Vorwaschung die Haut vor dem Jodanstrich ganz trocken war.

Die Wirkung der Jodtinktur auf pathogene Keime prüfte Noguchi in der Weise, daß er seine Fingerspitzen mit Aufschwemmungen von Staphylokokken und Streptokokken einrieb und nach dem Trocknen mit Jodtinktur bepinselte. Die Abimpfung nach 10 Minuten (Zahnbürstenmethode) ergab Keimfreiheit.

Versuche, die mit den gleichen Bakterienarten sowie mit Milzbrandsporen, B. coli, B. pyocyaneus nach Antrocknung auf sterilen Objektträgern vorgenommen wurden, bestätigten dieses Ergebnis. Alle vegetativen Bakterienformen waren schon 2 Minuten nach dem ersten Jodanstrich vernichtet, Milzbrandsporen nach dem zweiten Anstrich, und zwar gleichgültig, ob das Jod neutralisiert wurde oder nicht.

Hautversuche und Glasplattenversuche zeigten übereinstimmend, daß die stark keimtötende Wirkung der Jodtinktur wesentlich dem Jod zukommt und die eines jodfreien gleichprozentigen Alkohols $(86 \%)$ bei weitem übertrifft. Auch N. konnte, ähnlich wie schon früher andere Autoren (Brewitt, D use u. a.) durch die mikroskopische Untersuchung von Hautschnitten das Eindringen des Jods bis zu einer gewissen Tiefe, namentlich entlang der Haarbälge konstatieren.

Noguchi faßt seine Erfahrungen dahin zusammen, daß eine absolu te Sterilität der Haut und Hände überhaupt nicht erzielt werden kann, daß aber die Grossichsche Methode im bakteriologischen Experimente die übrigen Desinfektionsverfahren übertrifft.

Auch Brüning konnte sich von der stark keimtötenden Wirkung der Jodtinktur überzeugen. Er stellte fest, daß Granaten, dic mit B. pyocyaneus, Staphylococcus albus und B. coli infiziert waren, schon nach 1 Minute langem Verweilen in der 10 proz. Jodtinktur (in 96 proz. Alkohol) vollkommen sterilisiert wurden. Bei chemischer Neutralisation des Jods (5 proz. Natriumthiosulfatlösung) war die desinfizierende Kraft der Jodtinktur freilich herabgesetzt, doch bestand fast immer noch eine ausgesprochene Wachstumshemmung. Der 96 proz. Alkohol vermochte demgegenüber selbst nach einer balben Stunde die obenerwähnten Bakterien nicht abzutöten. Ganz gleiches erzielte Brüning bei Versuchen an der menschlichen Haut. Er fand ausge- 
sprochene keimtötende und wachstumshemmende Eigenschaften, so daß die klinisch bewährte Jodpinselung auch „billigen Anforderungen der Bakteriologie Genüge leistet". An der Wirkung der Jodtinktur auf die Hautbakterien sind nach seiner Auffassung drei verschiedene Faktoren beteiligt: Keimtötende Wirkung des Jods, fixierende Wirkung des Alkohols, 'stark hyperämisierende Wirkung der Jodtinktur.

Beyer hat bei dem Studium der Alkoholdesinfektion auch den Zusatz verschiedener desinfizierender Mittel, darunter insbesondere des Jods, hinsichtlich der Verstärkung der Alkoholwirkung geprüft. In zahlreichen Versuchen mit vielfach variierter Konzentration sowohl des Alkohols als des Jods konnte festgestellt werden, daß der Jodalkohol alle anderen Desinfektionsmittel an bactericider Kraft übertrifft und selbst Milzbrandsporen innerhalb 1 Minute abtötet. Dieses Ergebnis wurde erhalten bei Reagensglasversuchen (Aufschwemmungen, Seidenfäden) und bei Versuchen an der menschlichen Hand, wobei sowohl die "Tageshand" als auch die künstlich infizierte Hand (Staphylokokken) benutzt wurde. Ein besonderer Versuch zeigte, daß die Hand nach Desinfektion mit Jodtinktur bis in die Tiefe der Haut keimfrei war.

Kurz erwähnt seien noch die Versuche von Bon ne y und Browning. Diese Autoren empfehlen zur vorbereitenden Sterilisierung des Operationsfeldes Mischungen von Krystallviolett und Brillantgrün und kommen auf Grund bakteriologischer Kontrolle zu dem Resultat, daß die Jodtinktur diesem Verfahren an Wirksamkeit nachstehe.

In letzter Zeit hat sich alsdann Land $\mathrm{a} u$ in eingehenden Versuchen mit der Frage der Desinfektionswirkung der Jodtinktur beschäftigt. Auf Grund der bei umfangreichen Studien über die Frage der Händedesinfektion im Institut „Robert Koch" gesammelten Erfahrungen bediente er sich zunächst des Schumburgschen Verfahrens unter Bepinselung der Fingerkuppen. Nach vorangehendem Waschen wurden die Fingerkuppen mehrmals mit Jod bepinselt, bis sie dunkelbraun crschienen, und alsdann teils nach einfachem Antrocknen, teils nach Abwaschen mit Seifo durch Ausdrücken in verflüssigtem Nähragar, der später zum Erstarren gebracht wurde, auf Keimgehalt geprüft. Die Resultate waren wenig befriedigend und hielten den Vergleich mit der Desinfektionswirkung des Alkohols oder Sublimats nicht aus. Auch gegenüber künstlich auf die Hand gebrachten Bakterien (Kolibakterien) richtete die Jodtinktur beim Aufpinseln nicht viel aus; sie wirkte kaum günstiger als gegenüber den Bakterien der Tageshand.

Desinfektionsversuche am Unterarm, über die Landau in einer weiteren Arbeit berichtet, lieferten erheblich bessere Resultate. Hicr vermochte die Jodpinselung ungefähr das gleiche zu leisten, wie das Abreiben mit Alkohol. Die Technik bei den letzterwähnten Versuchen bestand darin, daß ein steriles Gazeläppchen, mit Pinzette gefaßt, 
in flüssigen Agar getaucht und hiermit eine etwa $3 \mathrm{qcm}$ große Hautstelle abgerieben wurde, worauf das Gazestückchen in einer. Schale mit flïssigem Agar ausgedrückt wurde; nach 2-3 maliger Wiederholung dieser Prozedur wurde das Läppchen schließlich im Agar belassen.

Wir kommen auf diese Versuche später zurück.

\section{Eigene Versuche.}

Die Versuche, über die im folgenden berichtet werden soll, zerfallen in 2 Gruppen. Die erste Gruppe umfaßt Reagensglasversuche, die zweite betrifft Versuche an der Haut, und zwar in der Hauptsache an der menschlichen Haut; einige wenige Versuche wurden auch an der Haut von Tieren (Meerschweinchen und Kaninchen) vorgenommen.

\section{A. Reagensglasversuche.}

Die Aufgabe bestand darin, die Desinfektionswirkung der Jodtinktur gegenüber verschiedenen Bakterienarten zu ermitteln und ganz besonders zu untersuchen, inwieweit der Jodgehalt die Desinfektionswirkung des Alkohols unterstützt und verstärkt. Zu diesem Zweeke wurde stets Alkohol gleicher Konzentration, aber ohne Jodzusatz, zur Kontrolle herangezogen.

Als Testbakterien wurden Kolibacillen, Staph. aureus und Pyocyaneusbacillen verwendet, teils in der Form von Aufschwemmungen in physiologischer $\mathrm{NaCl}-\mathrm{Lösung}$, teils in getrocknetem Zustande. In letzterem Falle gelangten kleine Leinwandläppchen von ca. $1 \mathrm{qcm}$ Größe, die mit Bouillonkulturen der betreffenden Bakterienarten getränkt waren, zur Verwendung. Die Aussaat der Proben, sowohl bei der Prüfung von Aufschwemmungen, als auch bei getrocknetem Bakterienmaterial, erfolgte gleichzeitig in Agar und Bouillon. Die Röhrchen wurden dann eine Woche lang bei $37^{\circ}$ gehalten und das Resultat erst nach dieser Beobachtungsdauer endgültig protokolliert. Weitere Einzelheiten sind bei den Versuchen besonders angegeben.

In jedem Versuche wurde außerdem das zur Prüfung verwendete Bakterienmaterial direkt, also ohne mit dem Desinfektionsmittel in Berührung zu kommen, auf Agar und Bouillon verimpft, um die gute Entwicklungsfähigkeit des Testmaterials festzustellen.

\section{Versuch I.}

$25 \%$ Alkohol $+2,5 \%$ Jod; Kontrolle mit 25\% Alkohol. Versuchsanordnung: 24stündige Agarkultur von Staph. aureus, sowie 48stündige Kulturen von $B$. coli und $B$. pyocyaneus wurden in je 5 $-6 \mathrm{ccm}$ NaCl-Lösung aufgeschwemmt. Nun wurde je I ccm einer mit Aq. dest. zu gleichen Teilen vermischten 10 proz. Jodtinktur mit je $1 \mathrm{ccm}$ der Aufschwemmung verdünnt, so daß ein ca. 25 proz. Alkohol 
mit einem Jodgehalt von 2,5\% zur Einwirkung gelangte. Zur Kontrolle wurde $1 \mathrm{ccm} 50$ proz. Alkohol mit je $1 \mathrm{ccm}$ der Bakterienaufschwemmung versetzt.

Kontrollen auf Entwicklungsfähigkeit (Kontrolle A).

Eine weitere Kontrolle sollte feststellen, ob bei Aussaat der desinfizierten Proben die noch anhaftenden und mit übertragenen Spuren der Jodlösung bzw. des Alkohols etwa entwicklungshemmend nachwirken. Es wurde zu diesem Zwecke je 1 Tropfen der Jodlösung (Alkohols) auf Agar bzw. Bouillon gebracht und die so vorbehandelten Röhrchen mit den Testbakterien beimpft (Kontrolle B).

Untersuchungsergebnis ${ }^{1}$ ): Es zeigte sich, daß ein Jodzusatz von $2,5 \%$ dem 25 proz. Alkohol eine außerordentliche Desinfektionskraft verleiht. Sämtliche Bakterienproben sind nach einer Einwirkungsdauer von 1 Minute abgetötet, während der 25 proz. Alkohol allein selbst nach 60 Minuten die Bakterien noch lebensfähig läßt. Wie Kontrolle B zeigt, übt die mitübertragene Menge der Jodlösung nur eine ganz geringfügige Entwieklungshemmung aus, so daß das günstige Ergebnis in der Hauptsache auf direkt bakterientötender Wirkung des Jodalkohols beruht.

Versuch II.

Offizinelle. Jodtinktur $(96 \%$ Alkohol $+10 \%$ Jod $)$; Kontrolle mit Alkohol absol. (ca. 96\%).

Versuchsanordnung: 24 stündige Kulturen von Staph. aureus, B. Coli und B. Pyocyaneus wurden in je $2 \mathrm{ccm} \mathrm{NaCl-Lösung} \mathrm{aufge-}$ schwemmt und die Aufschwemmungen, zur Beseitigung gröberer Partikelchen, durch steriles Filtrierpapier filtriert. Je 2 Tropfen dieses Filtrates wurden zu $2 \mathrm{ccm}$ einer 10 proz. Jodtinktur bzw. eines Alkohol absol. zugefügt.

Untersuchungsergebnis: Das Resultat dieses Versuches war, daß sämtliche Bakterienproben sowohl durch die Jodtinktur als auch durch den absoluten Alkohol binnen einer Minute abgetötet wurden. Eine Verstärkung der Desinfektionskraft des Alkohols durch den Jodzusatz trat bei dieser Versuchsanordnung nicht zutage, weil eben schon der Alkohol für sich energische Abtötung bewirkte. Das sei besonders hervorgehoben gegenüber der vielfach verbreiteten Anschauung, daß dem Alk. abs. nur eine unvollkommene Desinfektionskraft zukomme. Bei feuchtem Bakterienmaterial ist diese Desinfektionswirkung einc sehr intensive.

Der Einfluß des Jods zeigte sich bei Versuch II lediglich darin, daß eine wie bei Versuch I ausgeführte Kontrolle B eine gewisse Entwicklungshemmung erkennen ließ.

1) Auf eine Wiedergabe der Protokolle wird hier und bei den folgenden Reagensglasversuchen der Raumersparnis wegen verzichtet. 
Um den Verhältnissen der Praxis, wie sie bei der Grossichschen' Methode vorliegen, auch im Reagensglasversuche näher zu kommen, erstreckten sich die weiteren Prüfungen auf getrocknetes Bakterienmaterial. Hierbei bot sich zugleich Gelegenheit, eine nachträgliche Entwicklungshemmung durch anhaftende Spuren des Desinfektionsmittels mittels chemischer Neutralisierung auszuschalten und den Desinfektionseffekt ganz rein zu erhalten:

\section{Versuch III.}

Offizinelle Jodtinktur bzw. Alk, abs, geprüft gegenüber angetrockneten Bakterien. Vor der Aussaat keine Neutralisierung.

Versuchsanordnung: Die mit den Testbakterien imprägnierten und gut getrockneten Leinenläppchen werden in die Desinfektionslösung gelegt, wobei darauf geachtet wird, daß sie von der Flüssigkeit vollkommen bedeckt sind und sich damit vollsaugen. Vor der Uthertragung auf die Nährböden werden die Läppchen nur mit steriler NaClLösung abgespült.

Untersuchungsergebnis: Der absolute Alkohol läßt gegenüber angetrocknetem Bakterienmaterial im Stiche; nur Pyocyaneusbakterien zeigen nach 60 Minuten eine verminderte Entwicklungsfänigkeit. Dagegen sind bei Berührung mit Jodtinktur Colibakterien auch bei dieser Versuchsanordnung nach 1 Minute, Staphylokokken und Pyocyaneusbakterien nach 5 Minuten nicht mehr entwicklungsfähig.

$\mathrm{Ob}$ das günstigere Resultat des Jodalkohols nur auf Bakterienabtötung oder zugleich auch auf nachträglicher Entwicklungshemmung beruhte, mußte in diesem Falle weiter geprüft werden, denn bei der Art der Utbertragung der Testproben erscheint hier eine Nachwirkung der Jodtinktur weit leichter möglich, als bei der Prüfung von Bakterienaufschwemmungen. Es leuchtet ein, daß die Jodtinktur, die von den Stoffstückchen aufgesaugt ist, intensiver und länger nachwirken kann.

Der nüchste Versuch klärt diese Frage.

\section{Versuch IV.}

Die Versuchsanord nung ist genau die gleiche wie in Versuch 1II, nur mit dem Unterschied, daß die Leinwandläppchen vor der Utbertragung auf Agar oder Bouillon mit einer 10proz. Lösung von Natriumthiosulfat neutralisiert und dann mit $\mathrm{NaCl}$-Lösung abgespült werden. Die Alkoholläppchen werden nur mit NaCl-Lösung abgespült.

Untersuchungsergebnis: Hier zeigt sich, daß in der Tat die den Proben anhaftenden Spuren der Jodtinktur von Einfluß sind. Die Beseitigung dieser Spuren auf dem Wege chemischer Neutralisierung gibt weniger günstige Resultate. Nur Colibakterien werden auch 
bei dieser Versuchsanordnung, d. h. unter Ausschaltung entwicklungshemmender Nachwirkung, nach 1-5 Minuten abgetötet; Pyocyaneusbakterien gehen erst nach 10-15 Minuten zugrunde und Staphylokokken waren in dem vorliegenden Versuch selbst nach 30 Minuten noch nicht sicher abgetötet. Freilich zeigten Staphylokokken nach 15 und 30 Minuten schon eine sehr bedeutende Verminderung der Keimzahl.

Das, worauf es wesentlich ankommt, ist aber die Tatsache, daß auch gegenüber getrocknetem Bakterienmaterial der Jodgehalt der Jodtinktur von Bedeutung ist und die Abtötung herbeiführt. Die Alkoholproben blieben auch in diesem Versuche noch nach 1 stündiger Einwirkung voll entwicklungsfähig.

Es sollte daher weiterhin ermittelt werden, ob etwa ein geringerer Jodzusatz schon genügt, der Jodtinktur desinfizierende Wirkung zu verleihen. Diese Frage wird durch die beiden folgenden Versuche (V und VI) beantwortet. Von einer vergleichenden Prüfung mit Alkohol absol. wurde abgesehen, da die Versuche III und IV die allgemein bekannte Tatsache bestätigt hatten, daß getrocknete Bakterien der Wirkung des absoluten Alkohols lange widerstehen; in unseren Versuchen waren sie, wie erwähnt, nach 1 Stunde noch voll entwicklungsfähig geblieben.

In den Versuchen V und VI, die sich in der Ausführung der bei Versuch IV erwähnten Technik genau anschlossen, wurden also die Läppchen vor der Utbertragung auf Agar und Bouillon zunächst mit Natriumthiosulfatlösurig $(10 \%)$ behandelt und mit NaCl-Lösung abgespült. Bei Versuch V wurde außerdem zur Kontrolle eine Probereihe aus dem Desinficiens dire $k t$, ohne chemische Neutralisierung des Jods, zur Aussaat gebracht.

Für Versuch V wurde eine 5proz. Jodtinktur, für Versuch VI eine 2,5 proz. verwendet, unter Benutzung von Alkohol absol.

Untersuchungsergebnis: Zunächst ergibt auch hier wieder der Versuch mit 5 proz. Jodtinktur einen Unterschied der Resultate, je nachdem die Jodtinktur von den Läppchenproben nur abgespült (physiologische Kochsalzlösung) oder auf chemischem Wege beseitigt wird. In ersterem Falle zeigten sämtlich Testobjekte schon nach einer Einwirkungsdauer von 1 Minute keine Entwicklungsfähigkeit mehr. Daß hier keine völlige Abtötung, sondern nur Entwicklungshemmung vorlag, geht aus den Serien mit nachträglicher Neutralisierung des Jods hervor. Hierbei waren Staphylokokken erst nach 60 Minuten, Coli- und Pyocyaneusbakterien sicher nach 30-60 Minuten abgetötet.

Ganz ähnliche Ergebnisse lieferte Versuch VI, indem auch die 2,5 proz. Jodtinktur nach 30-60 Minuten bakterientötend wirkte, Pyocyaneusbakterien sogar nach dieser Zeit in einem Röhrchen noch entwicklungsfähig blieben. 
Während somit ein 10 proz. Jodgehalt der Jodtinktur nicht nur entwicklungshemmende, sondern auch deutliche bakterientötende Kraft verleiht, läßt ein geringerer Jodgehalt von 2,5-5\% nur geringe bactericide Eigenschaften, dagegen immer noch recht erhebliche ontwicklungshemmende Wirkung hervortreten.

\section{Versuch VII.}

70 proz. Alkohol mit einem Jodgehalt von etwa $\left.4,5^{0} /{ }^{1}\right)$; Kontrolle mit 70 proz. Alkohol.

Die Tatsache, daß besonders dem 70 proz. Alkohol eine stark bactericide Kraft auch gegenüber getrockneten Bakterien innewohnt, gab den Anlaß weiterhin zu untersuchen, inwieweit etwa auch hier ein Jodzusatz diese Wirkung noch zu verstärken vermag. Vorversuche hatten gezeigt, daß sich eine klare Jodlösung in 70 proz. Alkohol bis zu einem Jodgehalt von etwa 4,5\% herstellen läßt. Eine solche Lösung wurde zu den Versuchen verwendet.

Die Versuchsanordnung ist genau die gleiche wie in den oben erwähnten Versuchen, d. h. das Testmaterial an Leinenläppchen angetrocknet. Die Läppchenproben werden teils mit, teils ohne Neutralisierung auf die Nährböden verimpft. Der Alkohol wird von den Läppchen nur mit physiologischer NaCl-Lösung abgespült.

Untersuchungsergebn is: Ein Einfluß des Jods konnte bei dieser Versuchsanordnung nicht ermittelt werden, da schon der 70 proz. Alkohol allein (ebenso wie der Jodalkohol) innerhalb 1-5 Minuten die Testbakterien abtötete.

Zusammenfassend läßt sich über die erste Gruppe unserer Versuche sagen, daß die Jodtinktur sowohl gegenüber feuchtem, als auch gegenüber getrocknetem Bakterienmaterial stark entwicklungshemmende Einflüsse äuBert, daneben aber a uch eine entschiedene Abtötungskraft. Für diese Wirkung ist der Jodgehalt mit verantwortlich zu machen.

\section{B. Versuche an der menschlichen Haut.}

Naturgemäß gestatten Reagensglasversuche noch kein endgültiges Urteil über die Wirkung eines Präparates bei der praktischen Anwendung als Hautdesinficiens. Die folgenden Versuchsreihen erstrecken sich auf die Prüfung der Jodtinktur bei Behandlung der Haut nach dem Grossichschen Verfahren. Als Hautstellen wurden bei den meisten Versuchen Handfläche und Handrücken gewählt, in einem Versuch auch die Haut des Unterarms. In der Regel wurde so verfahren, daß

1) $100 \mathrm{ccm}$ Alkohol, $70 \%$, wurden mit $10 \mathrm{~g} \mathrm{Jod} \mathrm{versetzt} \mathrm{und} 24$ Stunden im Schüttelapparat geschüttelt. In der abfiltrierten Lösung wurde das Jod maßanalytisch bestimmt. 
dic betreffende Hautstelle ohne jede vorherige Vorbereitung, insbesondere ohne jede vorherige Waschung mehrmals hintereinander kräftig mit der Jodtinktur eingepinselt wurde. Zur Kontrolle wurde eine benachbarte Hautstelle in gleicher Weise mit Alkohol behandelt.

Die Wirkung des Jodanstrichs wurde in der Weise festgestellt, da B von einer Kontrollhautstelle zunächst vor der Pinselung eine Probe zur Aussaat gelangte, dann nach gewissen Zeiten von den mit Jodtinktur bzw. Alkohol eingeriebenen Stellen. Die Probeentnahme fand nach 5 bzw. 10, 15 und 20 Minuten statt. Die Technik der Materialentnahme war die, daß die betreffende Hautstelle mit einem in sterile Bouillon getauchten Tupfer (Diphtherietupfer) gründlich angefeuchtet und $\mathbf{a b}$ gerieben und der Tupfer dann auf Nährböden (Agar und Bouillon) ausgestrichen bzw. ausgeschüttelt wurde. Von den jodierten Hautstellen wurden stets 2 Proben entnommen, eine in der eben geschilderten Weise, die andere nach vorheriger Neutralisierung des Jods (10\% Natriumthiosulfatlösung) und Nachspülung mit NaCl-Lösung. Die Versuchsröhrchen wurden, wie auch in Versuchsgruppe $A$, eine Woche lang beobachtet, das Resultat nach 24 Stunden und am Ende der Beobachtungsdauer protokolliert. Die Aufbewahrung der Kulturen geschah teils bei Zimmer-, teils bei Bruttemperatur.

\section{Versuch VIII.}

Versuch VIII umfaßt eine größere Zahl von Einzelversuchen. Die Mehrzahl dieser Versuche wurde an der „Tageshand“ vorgenommen, um den Verhältnissen der Praxis und dem eigentlichen Zweck des Grossichschen Verfahrens tunlichst Rechnung zu tragen. Nur in zwei Versuchen wurde die mit B. prodigiosus künstlich infizierte Hand zur Prüfung herangezogen.

Wie die Erfahrung lehrt, können Desinfektionsversuche an der menschlichen Hand mehr oder minder abweichende Resultate ergeben, je nach den physiologischen Besonderheiten, die die Haut der verschiedenen Personen aufweist. Es wurde deshalb Wert darauf gelegt, eine größere Reihe von Personen zu diesen Versuchen heranzuziehen.

In Tabelle 1 sind die Resultate aller dieser Versuche zusammengestellt.

Es ergibt sich hieraus zunächst eine weitgehende Utbereinstimmung mit den in vitro erzielten Resultaten, insofern als von den jodierten Hautstellen bei einfacher Abimpfung gewöhnlich keine oder nur spärliche Bakterien wuchsen, nach Neutralisierung des Jods dagegen noch entwicklungsfähige Keime nachweisbar waren. Also auch hier neben einer bactericiden Wirkung eine entschiedene Entwicklungshemmung oder, im Sinne der früher zitierten Autoren (Kutscher, Decker), eine verminderte Keimabgabefähigkeit der Haut. Es ist natürlich nicht aus- 
zuschließen, daßs in den Fällen, in denen nur vereinzelte Kolonien aufgingen oder etwa nur in der Bouillon, nicht aber auf dem Agar Wachstum auftrat, es sich um Keime handelt, die erst nachträglich aus der Luft auf die jodierte Hautstelle gelangt sind, und so ein an sich günstiges Resultat in ein scheinbar weniger günstiges verwandelt haben. Diese Möglichkeit ist um so mehr in Betracht zu ziehen, als wir die Proben erst nach 5-20 Minuten entnahmen. Es ist hierauf übrigens schon von anderer Seite (Brüning) hingewiesen worden.

Die Wirkung des absoluten Alkohols steht nach unseren Versuchen hinter der der Jodtinktur zurück. Sie ist, wenn wir die rein bactericide Seite ins Auge fassen, ungefähr die gleiche, doch fehlt ihr das stark entwicklungshemmende Moment, das bei der Jodtinktur fast in allen Versuchen sofort in die Augen springt.

Bemerkenswert ist ferner, daß, eigentlich entgegen unseren Erwartungen, grundsätzliche Unterschiede in den Resultaten bei verschiedenen Personen, sowie bei Handfläche und Handrücken nicht erkennbar sind.

Die Versuche an der künstlich infizierten Hand stimmen in ihren Ergebnissen mit den Versuchen an der Tageshand überein (vgl. Tab. 1, Versuch 1 und $\mathrm{m}$ ). Die einfache Abimpfung 10 Minuten nach dem Jodanstrich läßt keine entwicklungsfähigen Keime zum Nachweis gelangen, die neutralisierte Probe dagegen liefert noch Kulturen. Aber auch hier ist, wie immer betont werden muß, die Keimverminderung sehr beträchtlich; so ist z. B. in dem ersten Versuch von der neutralisierten Probe auf dem Agarröhrchen nur eine einzige Kolonie zur Entwicklung gelangt.

\section{Versuch IX.}

In einem letzten Versuche wurden die Bedingungen nach verschiedenen Richtungen abgeändert. Zunächst wurde als Hautstelle die glatte Haut des Unterarms gewählt und als "Tageshaut" der Einwirkung des Jodalkohols ausgesetzt. Sodann gelangte, bei dem an 2 Personen ausgeführten Versuch, in dem einen Falle cine 10 proz. Jodlösung in Alkohol absolut., in dem anderen eine etwa 4,5 proz. Jodlösung in 70 proz. Alkohol zur Anwendung. Es sollte also geprüft werden, inwieweit die stärkere bactericide Wirkung, die der 70 proz. Alkohol in vitro gegenüber getrocknetem Bakterienmaterial äußert, etwa auch in der Form des Hautanstrichs zum Ausdruck gelangt. Endlich diente der Versuch zur Entscheidung der Frage, ob die Forderung Grossichs, die Jodpinselung ohne jede vorbereitende Säuberung (Waschung) der Haut vorzunehmen, für den Erfolg des Verfahrens nötig und unerläßliche Vorbedingung ist oder nicht.

Die Erfahrungen der Kliniker und Chirurgen gehen in dieser Hinsicht auseinander. Während die einen sich streng an die Grossichsche 
Methode halten und einfach die trockene ungewaschene Haut mit dem Jodanstrich versehen, haben andere von der vorhergehenden Waschung des Operationsfeldes nicht nur keinen Nachteil gesehen, sondern empfehlen sogar dieses Vorgehen als das zweckmäßigere (Nog uchi u. a.). Nur ist in dem letzteren Falle sorgfältig darauf zu achten, daß die Haut nach dem Waschen wieder vollkommen trocken geworden ist. Die Waschung wird daher gewöhnlich schon einige Stunden, bis zu 24 Stunden, vor der Jodpinselung vorgenommen. Die Waschung und Säuberung der Haut durch Rasieren zu unterstützen, ist gleichfalls von verschiedenen Seiten empfohlen, ohne daß dadurch der Erfolg der Jodpinselung beeinträchtigt würde. Nach persönlicher Erfahrung und mündlicher Bestätigung des Herrn Prof. Guggisberg wird beispielsweise in der hiesigen gynäkologischen Klinik das Operationsfeld gewöhnlich am Tage vorher durch gründliche Säuberung und Waschung vorbereitet.

Die Versuchsanordnung gestaltete sich im einzelnen so, daß der eine Unterarm der betreffenden Versuchsperson etwa eine halbe Stunde vor der Desinfektion mit Wasser und Seife gewaschen und nachher gründlich getrocknet wurde. Der andere Unterarm blieb ohne jede Vorbehandlung. Das Bepinseln der Haut mit Jodlösung, die Entnahme der Proben, die Aussaat der Proben mit und ohne Neutralisierung des Jods wurden im übrigen genau wie bei den früheren Handversuchen gehandhabt.

Das Ergebnis (vgl. Tab. 2) ist in mehrfacher Hinsicht interessant. Schon deswegen, weil die desinfizierende Wirkung des Jodanstrichs an der relativ glatten und bakterienarmen Haut des Unterarms weit vollkommener ist als an der faltenreicheren Haut der Hand. Alle Proben der jodierten Hautstellen erwiesen sich auch nach der Neutralisierung des Jods als steril, ein Resultat, das jedenfalls als außerordentlich günstig bezeichnet werden muß. Daß eine einzige Probe, und zwar gerade eine solche, die direkt ohne Neutralisierung ausgesät wurde, in dem Bouillonröhrchen Bakterienwachstum ergab, beruht offenbar auf Zufall oder nachträglicher Verunreinigung durch Luftkeime. Ein Unterschied zwischen der vorgewaschenen und nicht vorgewaschenen Haut ist nicht erkennbar, und dies spricht doch wohl entschieden zugunsten der vorherigen Waschung. Es wird hierbei, wie die Kontrollen zeigen, der Keimgehalt der Haut schon von vornherein herabgesetzt, und damit dem desinfizierenden Anstrich die Arbeit recht wesentlich erleichtert. Von einer Beeinträchtigung der. Alkohol- oder Jodwirkung ist in unseren Versuchen nichts zu bemerken; im Gegenteil erwiesen sich an den jodierten und auch an den nur mit Alkohol eingepinselten Stellen alle Hautbakterien als abgetötet. Bei Weglassen der Waschung ist das Ergebnis zwar bei Jodpinselung das 
grleiche, mit Ausnahme der einen, bereits oben erwähnten wohl durch Zufälligkeiten bedingten positiven Probe, dagegen führte in diesem Falle die Kontrollpinselung mit abs. Alkohol bzw. mit 70 proz. Alkohol nicht zu völliger Sterilität der Haut.

Bemerkenswerter Weise leistet der 70 proz. Alkohol mit einem Jodgehalt von nur etwa 4,5\% in der Form des Hautanstrichs das gleiche wie die 10 proz. Jodtinktur. Schon Brüning hat ähnliche Wahrnehmungen gemacht und auf Grund von Reagensglas- und Hautversuchen die Frage aufgeworfen, ob nicht vielleicht an Stelle der Jodtinktur der verdünnte Alkohol mit geringerem Jodgehalt mit gutem Erfolge zum Jodanstrich der Haut benutzt werden könne: Tatsächlich geschieht dies auch schon vielfach in den Kliniken und, wie es scheint, ohne daß ein Unterschied zwischen den verdünnten Jodlösungen und der offizinellen Jodtinktur konstatiert werden konnte. So gibt z. B. Noguchi an, daß man ursprünglich, infolge eines Mißverständnisses, in Deutschland eine 10 proz. Verdünnung der offizinellen Jodtinktur, also 1 proz. alkoholische Lösung des Jods mit zufriedenstellenden Resultaten angewendet habe.

Daß ein Jodgehalt von $5 \%$ in praktischer Hinsicht befriedigt und anscheinend das gleiche leistet wie die 10 proz. Jodtinttur, ergibt sich insbesondere auch aus den Erfahrungen der letzten Jahre. Unter dem Einfluß der Kriegsverhältnisse wurde vielfach die offizinelle Jodtinktur nur 5 prozentig hergestellt und hat sich auch in dieser Form im großen und ganzen bewährt. Hierbei ist freilich der konzentrierte Alkohol mit seiner keimfixierenden Wirkung, wie schon Brüning hervorhebt, von nicht zu unterschätzender Bedeutung. Ob auch der verdünnte (70 proz.) Alkohol mit einem geringeren Jodgehalt von etwa $4,5 \%$ bei der Hautpinselung die Jodtinktur ersetzen kann, ist unseres Wissens noch nicht systematisch untersucht worden. Die günstigen Ergebnisse, die unsere Versuche in Utbereinstimmung mit den Beobachtungen von Brüning geliefert haben, lassen Versuche nach dieser Richtung als angezeigt erscheinen.

\section{Versuche an der Haut von Tieren.}

Es handelt sich nur um wenige Versuche, die, gewissermaßen als Ergänzung der Beobachtungen an der Menschenhaut, an der Bauchhaut von 2 Meerschweinchen und 1 Kaninchen vorgenommen wurden. Die Versuche lehnen sich an die zuerst von Kutscher gewählte Technik an, indem von den behandelten Hautstellen kleine Stückchen herausgeschnitten und auf Nährböden verimpft wurden.

Zu dem Versuch dienten Tiere, die durch Entblutung getötet worden waren. Bei 2 Meerschweinchen wurde der Einfluß der Jodpinselung auf den Keimgehalt der Tageshaut geprüft, bei einem Kaninchen die Haut mit Bakterien (Staph. aureus) künstlich infiziert. 
Versuch X.

Die Bauchhaut eines entbluteten Meerschweinchens wird feucht unter Zuhilfenahme von Wasser und Seife in größerer Ausdehnung rasiert und 2 Stunden später zur Hälfte mit 10 proz. Jodtinktur und zur andern Hälfte mit abs. Alkohol kräftig mittels Wattebausch bestrichen. Excision kleiner Hautstücke erfolgt nach 10 Minuten. Utbertragung auf Agar und Bouillon. Bemerkt sei, daß die Haut auch nach vollständiger Antrocknung bzw. Verdunstung der zur Pinselung benutzten Flüssigkeit immer noch eine gewisse Feuchtigkeit besaß, was auch béi den anderen Tieren zu beobachten war. Eine so völlige Trockenheit, wie an der lebenden Menschenhaut, war bei diesen Tierexperimenten niemals zu erzielen.

Uber das Ergebnis vgl. unten.

\section{Versuch XI.}

Die Versuchsanordnung war genau die gleiche wie bei Versuch $\mathrm{X}$, nur mit dem einzigen Unterschied, daß die Haut vor dem Anstrich nicht gewaschen, sondern trocken rasiert wurde.

Das Ergebnis der Versuche $\mathrm{X}$ und XI, wie es Tab. 3 und 4 zeigen, ist insofern bemerkenswert, als auch hier die Vorbereitung der Ha ut mit Wasser und Seife (feuchtes Rasieren) nicht nur keinen Nachteil, sondern sogar eine gün stigere Wir kung zur Folge hatte. Die jodierten Hautstellen erwiesen sich als nahezu steril; nur die Bouillonröhrchen zeigten nach 8tägiger Beobachtung Wachstum. Der abs. Alkohol war in der Wirkung etwas schwächer. Bei Fortlassung der vorbereitenden feuchten Reinigung gab die Haut weniger günstige Resultate, indem alle Proben der jodierten Hautstelle nach 8 tägiger Beobachtung Bakterienwachstum zu erkennen gaben. Aber auch in diesem Fall war die Alkoholwirkung noch schwächer, die Proben der mit Alkohol behandelten Hautstellen zeigten schon am ersten Tage in Agar und Bouillon gutes Wachstum.

\section{Versuch XII.}

Die Bauchhaut eines entbluteten Kaninchens wird feucht (mit Seife und Wasser) rasiert und, nachdem sie wieder trocken geworden, mit einer Aufschwemmung einer 24 Stunden alten Agarkultur des Staph. aureus in physiologischer NaCl-Lösung infiziert. Die Infektion erfolgte mit Hilfe eines sterilisierten Wattebausches, der mit der Aufschwemmung getränkt und kräftig auf die betreffende Hautstelle eingerieben wurde. Nach abermaligem Trocknen der Haut erfolgt die Pinselung mit 10 proz. Jodtinktur. Auf eine Kontrolle mit jodfreiem Alkohol wurde diesmal verzichtet. Kleine Hautstücke wurden mittels steriler Schere und Pinzette nach 10 und 20 Minuten ausgeschnitten und auf Agar und Bouillon übertragen. 
Wie 'lab. 5 lehri, ist nach 20 Minuten eine völlige oder nahezu völligo Sterilisierung der Haut erfolgt. Auch schon nach 10 Minuten ist ein deutlicher Erfolg erkennbar. Der Versuch entspricht somit in seinem Ergebnis dem mit anderer Technik an der künstlich infizierten Menschenhaut erhobenen Befunde.

\section{SchluBbetrachtungen.}

Ubberblicken wir zum Schluß die Gesamtheit unserer Versuchsergebnisse, so ist zuerst die Tatsache hervorzuheben, daß der Jodgehalt der Jodtinktur oder, allgemeiner gesagt, der alkoholischen Jodlösungen auch in desinfektorischer Hinsicht von Bedeutung ist. Dies geht schon unzweideutig aus den Reagensglasversuchen hervor. Bei Benutzung von Bakterienaufschwemmungen in physiologischer $\mathrm{NaCl}$ Lösung, also bei einem feuchten Bakterientestmaterial, ist die bakterientötende Wirkung der Jodkomponente nicht ohne weiteres ersichtlich, da auch schon der jodfreie Alkohol selbst in der Form des ca 99 proz. (absoluten) Alkohols innerhalb kürzester. Zeit (1 Minute) bakterientötend wirkt. Wir möchten gerade diese letztere Tatsache unterstreichen, weil vielfach die Meinung vertreten wird, daß dem abs. Alkohol nur eine sehr beschränkte Desinfektionskraft zuzusprechen sei. Unsere Resultate finden sich vielmehr ganz im Einklang mit dem neuerdings namentlich von Ne ufeld vertretenen Standpunkt, daß der abs. Alkohol ein gutes, vielleicht sogar unser bestes Desinfektionsmittel für die Zwecke der Hautdesinfektion (Hände) darstellt, und daß seine Wirkung ausschließlich auf Keimabtötung beruht. Geringe Mengen von Feuchtigkeit genügen offenbar, um dem abs. Alkohol diese Wirkung zu verleihen, im Reagensglasversuch die minimale Flüssigkeitsmenge, die mit einer Öse der Bakterienaufschwemmung in den Alkohol übertragen wird, bei der Haustdesinfektion die Feuchtigkeit, die nach vorangehender Waschung der Haut noch anhaftet.

Handelt es sich dagegen darum, völlig getrocknetes Bakterienmaterial zur Abtötung zu bringen, so liegen die Verhältnisse anders. Hier fehlt in der Tat, wie wir bestätigen konnten, dem abs. Alkohol fast jede Desinfelztionskraft, so daß selbst lstündige Einwirkung nahezu wirkungslos bleibt. Dies zeigen Reagensglasversuche, die, wie freilich betont werden muß, übertrieben scharfe Bedingungen setzen und nicht mit den natürlichen Verhältnissen der Hautdesinfektion einfach identifiziert werden dürfen. Jedenfalls aber macht sich auch bei dieser Versuchsanordnung die Bedeutung des Jodzusatzes sehr bemerkbar. Zwar ist die Desinfektionskraft der Jodtinktur gegenüber getrockneten Bakterien nicht von gleicher Stärke wie gegenüber den in feuchtem Medium vorhandenen Bakterien, immerhin aber so ausgesprochen, daß diese Wirkung eben nur auf den Jodgehalt bezogen werden kann. 
Zugleich tritt aber hier noch eine andere Wirkung des Jods hervor. Sie charakterisiert sich als Entwicklungshemmung und läßt sich in verschiedener Weise darstellen. Einmal nämlich zeigt sich, daß auf Nährsubstraten, die nur mit einer geringen Spur von Jodtinktur versetzt sind, das Bakterienwachstum unter Umständen gehemmt bzw. verzögert wird, und ferner erhält man verschiedene Resultate bei Desinfektionsversuchen, je nachdem die aus der Jodlösung auf den Nährboden übertragenen Testbakterien vorher von dem anhaftenden Desinficiens chemisch befreit werden oder nicht.

Selbst ein verminderter Jodzusatz von $5 \%$ und $2,5 \%$ verleiht dem konz. Alkohol noch eine deutliche, wenn auch schwache Desinfektionskraft gegenüber getrockneten Bakterien, wobei freilich mit dem Jodgehalt von 2,5\% die Grenze erreicht zu sein scheint. Bei feuchtem Bakterienmaterial liegen die Verhältnisse für die Jodwirkung, wie schon erwähnt, erheblich günstiger. Hier vermag ein Zusatz von $2,5 \%$ Jod dem desinfektorisch fast ganz unwirksamen 25 proz. Alkohol eine solche Abtötungskraft zu verleihen, daß schon nach 1 Minute keine Bakterienentwicklung mehr zu erhalten ist.

Ganz ähnlich haben unsere Versuche an der menschlichen und tierischen Haut gezeigt, daß die Jodtinktur dem jodfreien Alkohol überlegen ist und sowohl bakterientötende als auch wachstumshemmende Eigenschaften äußert. Durch versehärfte Untersuchungsmethoden, insbesondere durch sorgfältige Neutralisierung des Jods vor der Probeentnahme, sowie im Tierexperiment durch Ubertragung ganzer Hautstückchen, ebenfalls nach chemischer Bindung des Jods, auf die Nährsubstrate konnte festgestellt werden, daß eine absolute Keimfreiheit der Haut durch den Jodanstrich nicht immer gewährleistet wird. Insofern also stimmen unsere Versuchsergebnisse mit den Angaben von $\mathrm{Ku}$ tscher, wenigstens bis zu einem gewissen Grade, überein. Andererseits müssen wir aber betonen; daß auch überall da, wo die jodierte Haut sich noch als keimhaltig erwies, eine erhebliche Keimverminderung zu verzeichnen war und daß doch eben vielfach sogar eine nahezu vollkommene Abtötung der Bakterien eintrat. Das gilt sowohl für die künstliche Infektion der Haut, als auch namentlich für die gewöhnlichen Hand- und Hautbakterien. Gerade die letztere Tatsache erscheint uns von Wichtigkeit, weil diese besonders in den tieferen Teilen der Haut (Falten, Haarbälge, Schweißdrüsen) haftenden und schwer erreichbaren Bakterien der Einwirkung eines Desinficiens nicht leicht zugänglich sind.

$\mathrm{Zu}$ der bakterientötenden Wirkung des Jods kommt als ein weiterer wesentlicher Faktor bei der Hautpinselung die entwicklungshemmende Eigenschaft der Jodtinktur hinzu, wie sie sich durch Untersuchung der jodierten Haut ohne Neutralisierung des Jods erweisen läßt. 
$\mathrm{DaB}$ in den Versuchen Landa us an den Fingerkuppen das Jod so wenig befriedigende Resultate gab und an die Desinfektionswirkung der Alkoholwaschung nicht heranreichte, dürfte wohl in erster Linie an der Wahl der Hautstelle liegen. Bei dem Eintauchen und Ausdrücken der Fingerkuppen in dem Nährboden werden die unter den Nägeln und in den Nägelfalzen haftenden Keime mit zur Aussaat gebracht, also Keime von Stellen, die der Einwirkung des aufgepinselten Jods nur schwer zugänglich sind. Hierdurch wird der Prüfungsmodus, der gewiß die Vorzüge der schärfsten Kontrolle besitzt, durch ein Moment kompliziert, das streng genommen von der reinen Desinfektionskraft des Mittels zu scheiden ist. In Ċbereinstimmung mit dieser Auffassung hat denn auch Landa $u$, wie bereits erwähnt, bei der Wahl anderer Hautstellen, nämlich des Unterarms, wesentlich bessere Resultate erhalten und einen nennenswerten Unterschied zwischen der Jodpinselung und der Alkoholwaschung nicht feststellen können. Wenigstens möchten wir im Hinblick auf unsere eigenen Experimente für die verschiedenen Resultate, die Landa $\mathbf{u}$ an den Fingerkuppen und an der Haut des Unterarms erhalten hat, den Unterschied in der Beschaffenheit des Desinfektionsgebietes als wesentlich betrachten. Die günstigen Ergebnisse an der Haut des Unterarms nur auf den weniger scharfen Prüfungsmodus des Abreibens mit Gazestückchen zurückzuführen, will uns nicht ganz einleuchtend erscheinen.

Die völlig negativen Ergebnisse, die Kutscher mit der Jodbehandlung erhalten hat, dürften wohl darauf zurückzuführen sein, daß er bei seinen Hautexperimenten ungewöhnlich schwere Versuchsbedingungen gesetzt hat, die sich von den natürlichen Verhältnissen zu weit entfernen. Die Wahl der Milzbrandsporen zur Infektion von Kaninchen and die Jodbehandlung der infizierten Hautstelle erst 24 Stunden nach der Infektion lassen eigentlich von vornherein kaum ein anderes Resultat erwarten als es $\mathrm{K} u$ tscher erzielt hat. Denn es handelt sich hier um einen hochinfektiösen Krankheitserreger, einen „Ganzparasiten“" im Sinne Bails, der die ausgesprochene Tendenz zur Weiterverbreitung im Gewebe auf dem Wege der Lymph- und Blutbahnen zeigt. Der Nachweis, daß die infizierten Hautstellen trotz Jodpinselung am nächsten Tage noch lebensfähige Keime enthalten, ist daher wohl nicht überraschend und es kann dieser Befund wohl auch nicht als Beweis gegen die baktericide Wirkung der Jodtinktur verallgemeinert werden. In gleicher Weise lassen sich auch die bei der Infektion mit B. pyocyaneus von $\mathrm{Kutscher}$ erhaltenen Resultate erklären, wenngleich bei dieser Bakterienart die Versuchsbedingungen eben milder sind. Immerhin bestehen wohl die Angaben Kutschers u. a. insofern zu Recht, als gegenüber einer Wundinfektion mit hochinfektiösen Mikroorganismen und bei relativ später Behandlung die Jodpinselung eine antibakterielle Wirksamkeit nicht mehr ausreichend entfalten kann. 
Wenn die günstigen Erfahrungen, die Kliniker und Bakteriologen im allgemeinen mit der Grossichschen Methode des Jodtinkturanstrichs gemacht haben, vielfach so aufgefaßt werden, daß die Keimabgabefähigkeit der Haut mehr oder minder herabgesetzt sei (Kutscher, Decker u. a.), so erklärt sich diese Erscheinung eigentlich schon zur Genüge durch die baktericide und entwicklungshemmende Wirkung der Jodtinktur. Es kann zweifelhaft sein, inwieweit es berechtigt ist, noch eine fixierende Wirkung besonderer Art als Erklärung anzunehmen. Es mag sein, daß eine solche Wirkung besteht, es mag auch sein, daß diese Wirkung, wie Brüning meint, schon dem Alkohol zukommt und nicht auf das Jod zu beziehen ist. Doch liegen hierfür, wie wir glauben, beweisende Anhaltspunkte kaum vor. Unsere eigenen Experimente lassen sich durch die festgestellten baktericiden und wachstumshemmenden Einflüsse der Jodtinktur in befriedigender Weise erklären, ohne daß die Hilfshypothese, die der Jodtinktur noch eine fixierende Wirkung zuschreibt, nötig wäre. Wir möchten in dieser Hinsicht auch auf die Ausführungen von Ne ufeld verweisen, der auf Grund seiner Untersuchungen über Händedesinfektion ebenfalls die Wirkung des Alkohols ausschließlich auf Keimabtötung, nicht aber auf Keimfixierung zurückführt und auch für die Jodtinktur die fixierende Wirkung leugnet. Man muß sich, wie wir glauben, vergegenwärtigen, wie die Deutung der Jodwirkung im Sinne einer Keimfixierung zustande gekommen ist. Sie wurde abgeleitet von den negativen Befunden, die man in baktericider und hemmender Hinsicht bei experimentellen Untersuchungen erhalten hatte. Worauf diese negativen Befunde zurückzuführen sind, bleibe hier zunächst unerörtert. Nachdem aber, wie unsere Versuche in Bestätigung der Angaben von Brüning und Nog u chi gezeigt haben, der Jodtinktur starke antibakterielle Einflüsse zuerkannt werden müssen, entfällt die Notwendigkeit, nach weiteren Erklärungen zu suchen.

Im Einklang mit der eben entwickelten Auffassung steht auch die Tatsache, daß eine dem Jodanstrich voraufgehende Waschung der Haut, cntgegen der ursprünglichen Forderung Grossichs, ohne. Nachteil angewendet werden kann. Klinische Praxis und experimentelle Prüfung haben gezeigt, daß die Befürchtung, man könne durch die aufquellende Wirkung der Wasser- und Seifebehandlung dem Effekt des Jodtinkturanstrichs entgegenarbeiten, tatsächlich nicht zu Recht besteht. Man stellte sich wohl vor, daß die in den tieferen Teilen der Haut befindlichen Bakterien unter dem fixierenden Einfluß der Jodtinktur in der Tiefe festgehalten, an dem Vordxingen an die Hautoberfläche gehindert und damit ungefährlich gemacht werden. Nun liegen aber die Verhältnisse offenbar so, daß die nach dem Waschen, Einseifen, Rasieren usw. der Haut an die Oberfläche gebrachten Bakiterien durch die glcichen 
Maßnahmen auch entfernt werden, so daß der Jodtinktur ihre bakterientötende und wachstumshemmende Wirkung keineswegs erschwert, sondern im Gegenteil erleichtert wird. Unsere eigenen Versuche lassen den Effekt dieser vorbereitenden mechanischen Reinigung klar hervortreten, indem die Kontrollproben von derartigen Hautstellen begreiflicherweise schon vor der Desinfektion einen ziemlich geringen Keim-. gehalt aufwiesen. Das gilt übereinstimmend für die Menschen- und Tierhaut (Meerschweinchen, Kaninchen).

Demgemäß waren auch die Resultate der Jodpinselung an der vorgewaschenen Haut günstiger, als an der unvorbereiteten Tageshaut.

Eine weitere Unterstützung erfährt die Deutung der Jodwirkung im Sinne direkt antibakterieller Einflüsse durch die Tatsache, daß auch Jodlösungen in verd ünntem (70 proz.) Alkohol im Hautexperiment ebenso günstige Ergebnisse liefern, wie die offizinelle Jodtinktur. Hier tritt doch die zusammenziehende, schrumpfende und „fixierende " Wirkung des Alkohols auf das Gewebe im Vergleich mit dem abs. Alkohol sicherlich sehr zurück und es bleibt in der Hauptsache die stark baktericide Eigenschaft des 70 proz. Alkohols, verstärkt durch die bakterientötende und entwicklungshemmende Jodwirkung. Wenigstens haben unsere Versuche, in Übereinstimmung mit ganz analogen Beobachtungen von Brüning, Bayer u. a., den 70 proz. Alkohol mit einem Jodgehalt von ca. 4,5\% der gewöhnlichen Jodtinktur $(10 \%)$ gleichwertig gefunden.

Es mag sein, daß noch andere Faktoren eine Rolle bei den Erfolgen des Grossichschen Verfahrens spielen, und daß, wie z. B. Brüning annimmt, der H y perämie ein Einfluß zukommt. Experimentelle Beweise hierfür zu erbringen, stößt freilich auf Schwierigkeiten. Aber, wie dem auch sei, liefert die Hautpinselung mit alkoholischer Jodlösung, insbesondere mit der offizinellen Jodtinktur, so befriedigende Resultate, wie man sie von einem zur Hautdesinfektion bestimmten Verfahren nur wünschen kann. Sie übertreffen nach unseren Versuchen in vitro und an der Haut selbst die Leistungen der reinen Alkoholdesinfektion und charakterisieren sich schon dadurch als sehr gute. Es sei in diesem Zusammenhange auch noch darauf hingewiesen, daß die Wirkung des Jodanstrichs mit der Länge der Zeit etwas zuzunehmen scheint. Das ist bereits von Noguchi betont worden und auch unsere eigenen Versuche haben nach 20 Minuten zum Teil noch günstigere Resultate ergeben, als nach 10 Minuten. Wir stimmen durchaus der Ansicht zu, daß eine völlige Sterilität der Haut mit absoluter Sicherheit wohl überhaupt kaum zu erzielen ist; nicht wegen Mangel an guten Desinfektionsmitteln und Methoden, sondern vor allen Dingen wegen der anatomischen Besonderheiten der Haut. Wir werden daher, selbst bei den besten Verfahren, also auch bei dem Jodanstrich, die Tatsache mit in den Kauf nehmen müssen, daß unter Umständen einmal ver- 
einzelte Hautkeime unbeeinflußt zurückbleiben. Hierin liegt aber unseres Erachtens vom rein bakteriologischen Standpunkt keine irgendwie nennenswerte Gefahr, weil diese Keime erfahrungsgemäß zu den harmlosen Saprophyten gehören und keine infektiösen Eigenschaften besitzen. Die klinische Erfahrung gibt uns hierin recht.

\section{Tabellen.}

Tabelle I.

Die folgende Versuchsanordnung bezieht sich auf die Versuche $a-d$.

Hand vorher nicht gewaschen. Desinfektion mit offizineller Jodtinktur ( $10 \%$ Jod in 96 proz. Alkohol) und Alk. abs. Von den Händen wird 5 Minuten nach der Desinfektion abgeimpft.

Versuch a: Volarfläche der eigenen linken Hand.

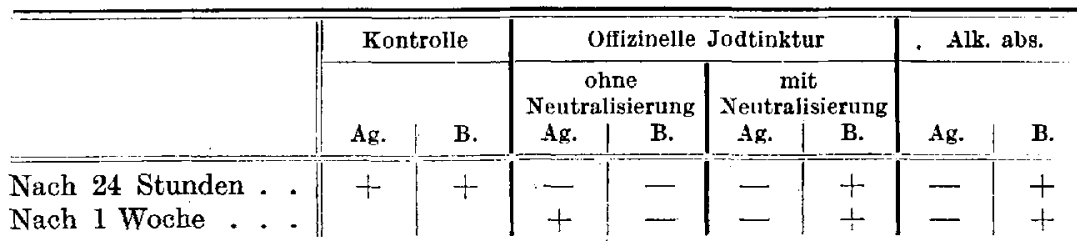

Versuch b: Volarfläche der rechten Hand, Herr Sch.

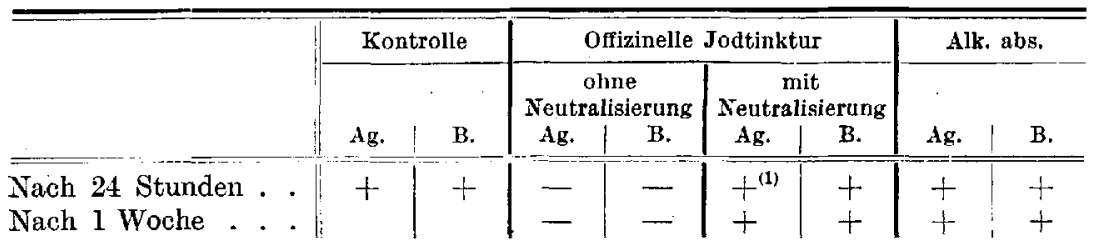

Versuch c: Volarfläche der rechten Hand, Herr F.

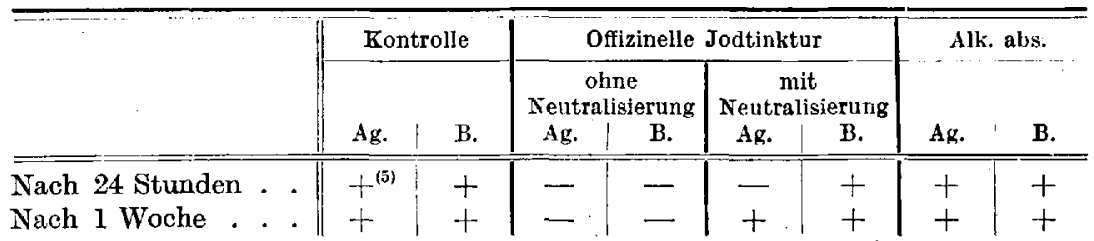

Versuch d: Volarfläche der rechten Hand, Herr G.

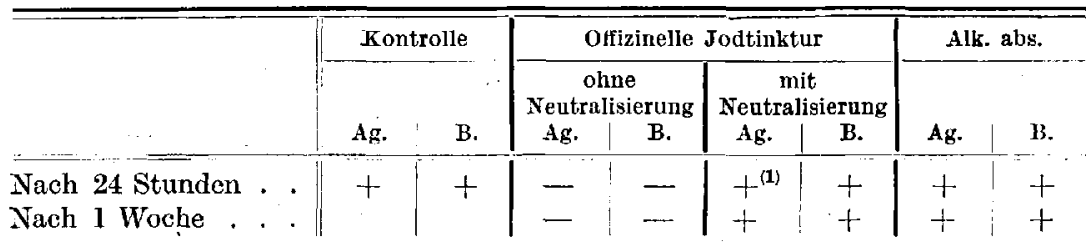


Die Versuchsanordnung für die Versuche e-i ist genau die gleiche wie oben, nur wird von den Händen 10 Minuten nach der Desinfektion abgeimpft.

Versuch e: Volarfläche der rechten Hand, Herr S.

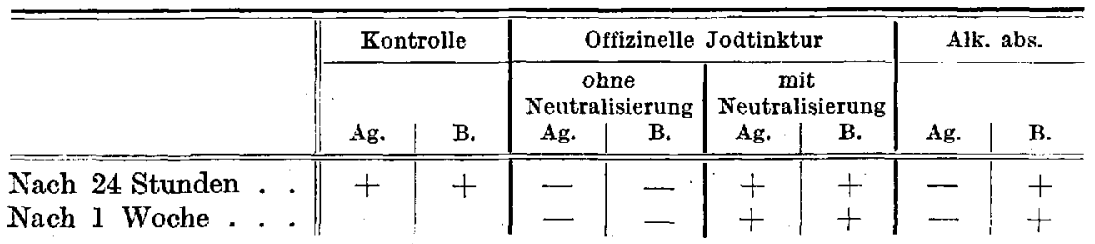

Versuch f: Volarfläche der rechten Hand, Frl. G.

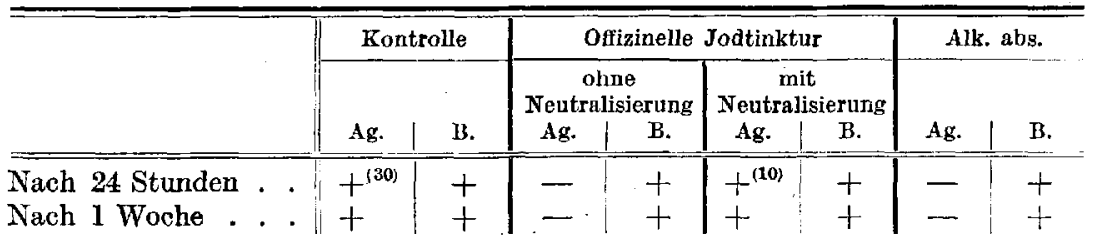

Versuch g: Handrücken der rechten Hand, Frl. G.

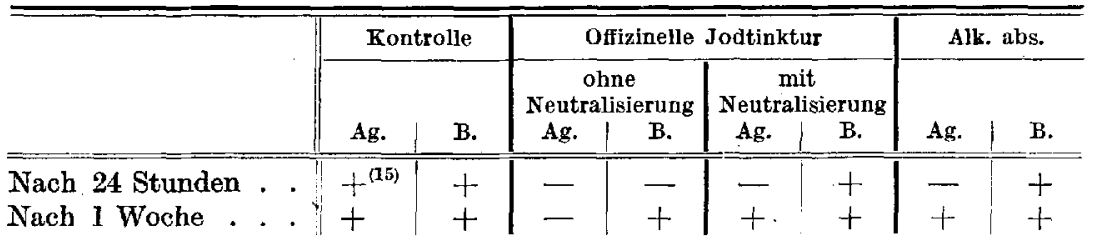

Versuch h: Volarfläche der rechten Hand, Frl. B.

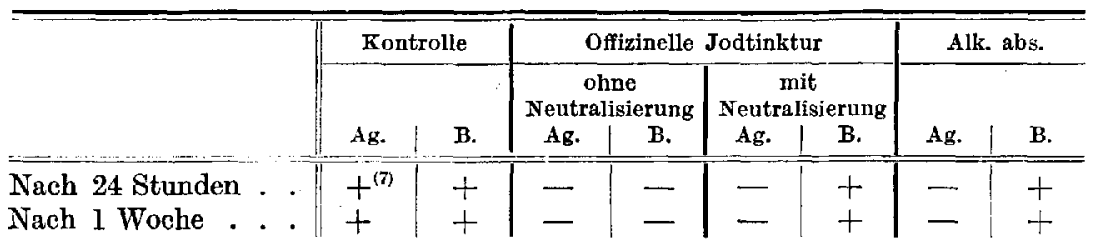

Versuch i: Handrücken der rechten Hand, Frl. B.

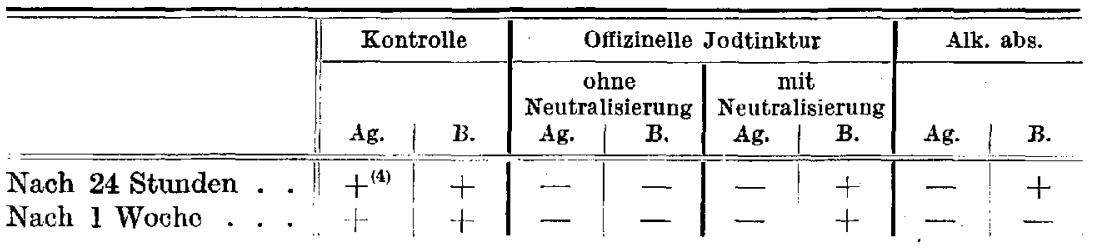


Versuchsanordnung wie bisher, nur abgeimpft nach 10 und 20 Minuten.

Versuch k: Volarfläche der linken Hand, Herr S.

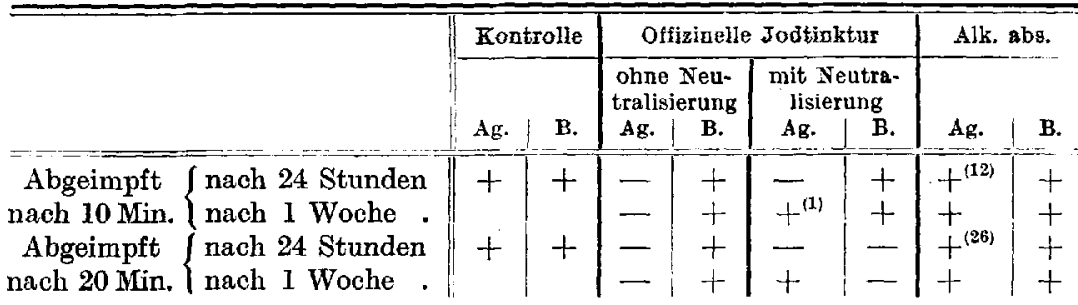

Versuch 1: Die Hand wurde vorher nicht gewasehen. Die Volarfläche der eigenen linken Hand wurde mit einer $\mathrm{NaCl}$-Aufschwemmung einer Prodigiosuskultur infiziert. (Zum Einreiben wurden sterile Diphtheriepinsel benutzt.) Nachdem die Hand trocken war, wurde sie mit offizineller Jodtinktur (10\% Jod in Alk. abs.) und mit Alk. abs. desinfiziert. Von den Händen wurde 10 Minuten nach der Desinfektion abgeimpft.

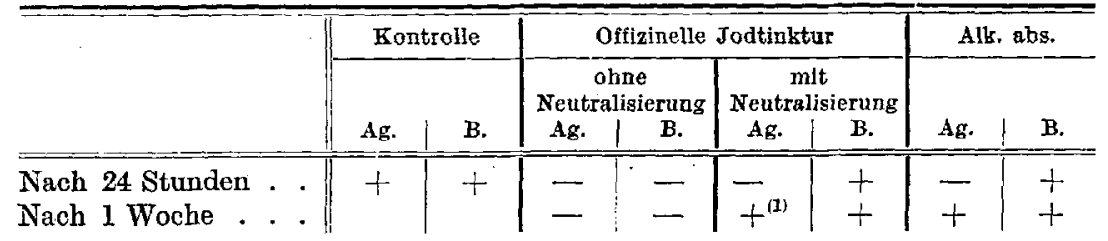

Versuch m: Die Versuchsanordnung ist genau die gleiche wie im vorigen Versuch. Volarfläche der rechten Hand, Herr R.

\begin{tabular}{|c|c|c|c|c|c|c|}
\hline \multirow[b]{2}{*}{$\cdot$} & \multicolumn{2}{|c|}{ Kontralle } & \multicolumn{2}{|c|}{ Orfizinelle Jodtinktur } & \multicolumn{2}{|c|}{ Alk. abs. } \\
\hline & Ag. & B. & \begin{tabular}{l}
\multicolumn{2}{c}{ ohne } \\
Neutralisierung \\
Ag. | B.
\end{tabular} & \begin{tabular}{|c}
\multicolumn{2}{c}{ mit, } \\
Neutralisierung \\
Ag. $\quad \mathrm{B}$.
\end{tabular} & Ag. & $\mathbf{B}$. \\
\hline $\begin{array}{l}\text { Nach } 24 \text { Stunden . . } \\
\text { Nach } 1 \text { Woche . . . }\end{array}$ & + & + & $+^{(1)} \mid-$ & $\overline{+}$ & $\bar{t}$ & $\begin{array}{l}+ \\
+\end{array}$ \\
\hline
\end{tabular}

Tabelle 2.

Versuch a: Die Beugefläche.des linken Vorderarms wurde etwa eine halbe Stunde vor der Desinfektion mit Wasser und Seife gewaschen und nachher getrocknet; die gleichnamige Stelle des rechten Vorderarmes wurde ohne jede Vorbehandlung der Desinfektion ausgesetzt. Eine Hautstelle wurde etwa 1 Minute lang mit Alk. abs. gewaschen, eine andere Hautstelle mit offizineller Jodtinktur bepingelt. Abgeimpft wurde nach 15 Minuten (Herr R.). 


\begin{tabular}{|ll|l|l|l|l|l|l|l|}
\hline Kontrolle & \multicolumn{3}{|c|}{ Offizinelle Jodtinktur } & \multicolumn{2}{|c|}{ Alk. abs. } \\
\hline & & & \multicolumn{2}{|c|}{ ohne } & \multicolumn{2}{|c|}{ mit } & & \\
Ag. & B. & Ag. & B. & Ag. & B. & Ag. & B. \\
\hline
\end{tabular}

Ohne vorherige Waschung.

\begin{tabular}{ll||l|l|l|l|l|l|l} 
Nach 24 Stunden . . & $+{ }^{(60)}$ & + & - & + & - & - & - & + \\
Nach 1 Woohe ... & + & + & - & + & - & - & - & +
\end{tabular}

Mit vorheriger Waschung.

\begin{tabular}{ll|l|l|l|l|l|l|l|l} 
Nach 24 Stunden . . & $+^{(12)}$ & + & - & - & - & - & - & - \\
Nach 1 Woche . . . & + & + & - & - & - & - & - & -
\end{tabular}

Versuch b: Die Versuchsanordnung ist genau die gleiche wie in Versuch a, nur wurde eine Jodlösung von ca. $4,5 \%$ Jod in $70 \mathrm{proz}$. Alkohol und ein 70 proz. Alkohol zur Desinfektion verwendet (Herr K.).

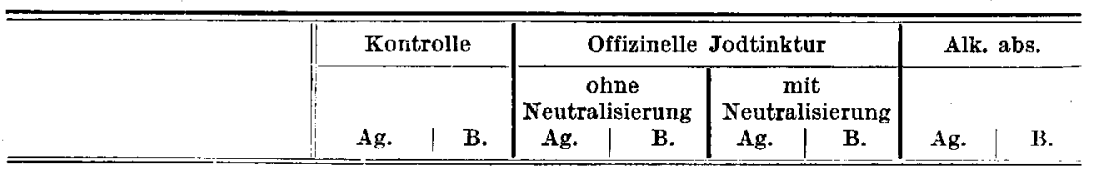

Ohne vorherige Waschung.

\begin{tabular}{ll|l|l|l|l|l|l|l} 
Nach 24 Stunden . . & + \\
Nach 1 Woohe . . & & + & - & - & - & - & 0 & +
\end{tabular}

Mit vorheriger Waschung.

\begin{tabular}{ll|l|l|l|l|l|l|l} 
Nach 24 Stunden . . & $+^{(18)}$ \\
Nach 1 Woche .. & $+\mid$ & - & - & - & - & - & - & - \\
${ }^{(40-50)}$ & + & - & - & - & - & - & -
\end{tabular}

Tabelle 3.

Die Bauchhaut eines durch Entblutung getöteten Meerschweinchens wurde feucht (mit Wasser und Seife) rasiert. 2 Stunden nach dem Rasieren wurde die Haut an 2 Stellen mit offizineller Jod tin $k t u r$ bzw. Alk. abs. desinfiziert. Nach 10 Minuten wurden kleine Hautstücke mittels steriler Pinzette und Schere ausgeschnitten und auf Agar und Bouillon übertragen.

\begin{tabular}{|c|c|c|c|c|c|c|c|c|}
\hline & \multicolumn{2}{|c|}{ Fontrolle } & \multicolumn{4}{|c|}{ Offizinelle Jodtinktur } & \multicolumn{2}{|c|}{ Alk. abs. } \\
\hline & \multirow{2}{*}{ Ag. } & \multirow{2}{*}{ B. } & \multicolumn{2}{|c|}{$\begin{array}{c}\text { ohne } \\
\text { Neutralizierung }\end{array}$} & \multicolumn{2}{|c|}{$\begin{array}{c}\text { mit } \\
\text { Neutralisierung }\end{array}$} & \multirow{2}{*}{ Ag. } & \multirow[b]{2}{*}{ B. } \\
\hline & & & Ag. & B. & Ag- & B & & \\
\hline $\begin{array}{l}\text { Nach } 24 \text { Stunden } \\
\text { Nach } 1 \text { Woche. }\end{array}$ & + & + & - & $\overline{+}$ & - & $\overline{+}$ & - & $\begin{array}{l}+ \\
+\end{array}$ \\
\hline
\end{tabular}

Tabelle 4.

Die Versuchsanordnung war genau die gleiche wie bei Tab. 3, nur mit dem einzigen Unterschied, daß die Haut vor dem Anstrich nicht gewaschen, sondern trocken rasiert wurde. 


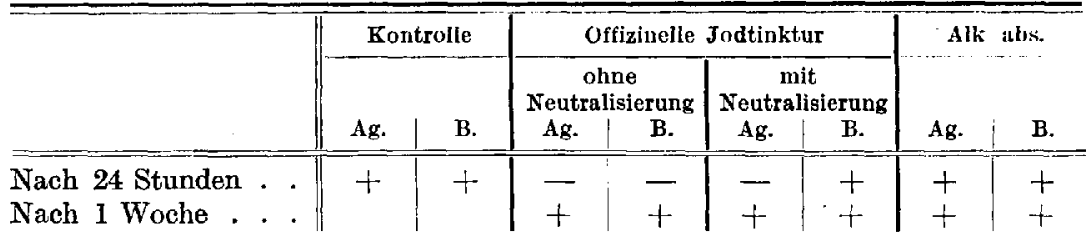

Tabelle 5 .

Versuch an der Bauchhaut eines entbluteten Kaninchens. Feucht rasiert und mit Aufschwemmung von Staph. a ur. infiziert. Pinselung mit 10 proz. Jodtinktur. Excision kleiner Hautstücke nach 10 und 20 Minuten; Aussaat in Agar und Bouillon.

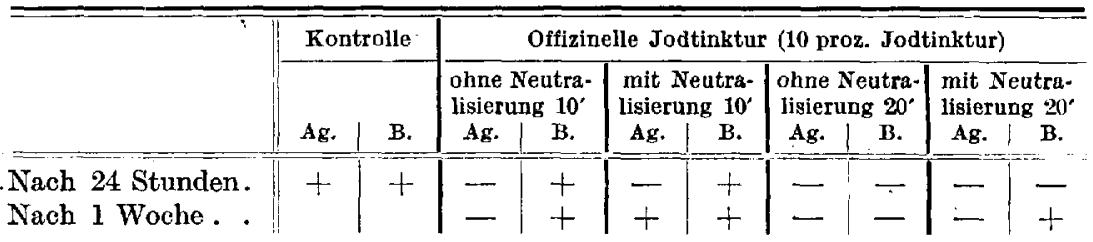

\section{Literaturverzeichnis.}

B érard u. Chat tot, Ref. Zentralbl. f. Chir. 1910, S. 1162. - Be yer, Zeitschr. f. Hyg. 70. 1912. - Bonney u. Browning, Brit. med. journ. 1918, S. 562. Brewitt, Münch. med. Wochenschr. 1910, Nr. 6. - Brüning, Arch. f. klin. Chir. 94. 1911. - Decker, Dtsch. med. Wochenschr. 1911, S. 1078. - Duse, Ref. Zentralbl. f. Chir. 1911, Nr. 23. - Grossich, Berl. klin. Wochenschr. 1909, Nr. 43. - Jungengel, Münch. med. Wochenschr. 1910, S. 629. - Kutscher, Berl. klin. Wochenschr. 1910, Nr. 47. - La nda u, Berl. klin. Wochenschr. 1918, Nr. 28. - Landa u, Arch. f. klin. Chir. 113. - Lanz, Zentralbl. f. Chir. 1910, Nr. 25. - Myauchi, Dtsch. med. Wochenschr. 1910, Nr. 30. - Ne ufeld, Dtsch. med. Wochenschr. 1918. - Noguchi, Arch. f. klin. Chir. 96. 1911. - Osaki, zit. nach Noguchi. - Walther u. Touraine, Bull. et mém. de la soc. de chir. de Paris 1909, Nr. 10 u. 12. 